\title{
UJI FITOKIMIA DAN AKTIVITAS ANTIOKSIDAN DARI RUMPUT LAUT Sargassum sp. DENGAN METODE PENGERINGAN YANG BERBEDA
}

\author{
Phytochemical and Antioxidant Activity Tests of Seaweed Sargassum sp. with Different Drying Methods
}

\author{
Fazirul Maulana*, Asnani, Haslianti \\ Jurusan Teknologi Hasil Perikanan, Fakultas Perikanan dan Ilmu Kelautan Universitas Halu Oleo, Kendari, \\ Sulawesi Tenggara, Indonesia \\ *Email korespondensi: anharullah.teknik@gmail.com (Telp: +6285298211078) \\ Diterima: 14 Maret/ Disetujui 19 April 2021
}

Cara sitasi: Fazirul M, Asnani, Haslianti. 2021. Uji Fitokimia dan Aktivitas Antioksidan dari Rumput Laut Sargassum sp. dengan Metode Pengeringan yang Berbeda. Jurnal Fish Protech. 4(1):86-92.

\section{ABSTRACT}

Sargassum sp. is the most abundant type of seaweed from the brown algae group (Phaeophyceae) which is spread in tropical waters. The aim of this study was to determine the phytochemical content and antioxidant activity of the extract of Sargassum sp. with different drying methods. Sargassum sp. dried using room temperature $\left( \pm 25^{\circ} \mathrm{C}\right)$ for 21 days and oven $\left(40^{\circ} \mathrm{C}\right)$ for 30 hours, then extracted using methanol. Phytochemical tests were carried out to determine the presence of alkaloids, tannins, flavonoids, saponins, steroids and triterpenoids. The antioxidant activity of the seaweed extract of Sargassum sp. tested by the DPPH method (1-1-diphenyl-2-picrylhydrazyl). Phytochemical test results of the extract Sargassum sp. flavonoids, saponins, triterpenoids and steroids, while alkaloids and tannins were not found. The value of antioxidant activity in the methanol extract of Sargassum sp. shows a higher room temperature treatment with an IC 50 value of $823.652 \mathrm{ppm}$ compared to a treatment temperature of $40^{\circ} \mathrm{C}$ with an $I C_{50}$ value of $914.1920 \mathrm{ppm}$. The drying method affects the antioxidant activity of Sargassum sp.

Keywords: Sargassum sp., drying, extraction, phytochemicals, antioxidants.

\section{ABSTRAK}

Sargassum sp. merupakan jenis rumput laut paling melimpah dari kelompok alga coklat (Phaeophyceae) yang tersebar di perairan tropis. Tujuan penelitian adalah untuk mengetahui kandungan fitokimia dan aktivitas antioksidan ekstrak Sargassum sp. dengan metode pengeringan yang berbeda. Sargassum sp. dikeringkan menggunakan suhu ruang $\left( \pm 25^{\circ} \mathrm{C}\right.$ ) selama 21 hari dan oven (suhu $40^{\circ} \mathrm{C}$ ) selama 30 jam, kemudian diekstrak menggunakan pelarut metanol. Uji fitokimia dilakukan untuk mengetahui keberadaan senyawa alkaloid, tanin, flavonoid, saponin, steroid dan triterpenoid pada ekstrak. Aktivitas antioksidan ekstrak rumput laut Sargassum sp. diuji dengan metode DPPH (1-1-difenil-2pikrilhidrazil). Hasil uji fitokimia pada ekstrak Sargassum sp. yang dikeringkan pada suhu ruang dan suhu $40^{\circ} \mathrm{C}$ ditemukan adanya flavonoid, saponin, triterpenoid dan steroid sedangkan alkaloid dan tannin tidak ditemukan. Nilai aktivitas antioksidan pada ekstrak metanol Sargassum sp. menunjukan perlakuan suhu ruang lebih tinggi dengan nilai $\mathrm{IC}_{50} 823,652 \mathrm{ppm}$ dibandingkan perlakuan suhu $40^{\circ} \mathrm{C}$ dengan nilai $\mathrm{IC}_{50} 914,1920 \mathrm{ppm}$. Metode pengeringan berpengaruah terhadap aktivitas antioksidan dari Sargassum sp.

Kata kunci: Sargassum sp., pengeringan, ekstraksi, fitokimia, antioksidan.

\section{PENDAHULUAN}

Sargassum sp. merupakan jenis rumput laut yang sangat melimpah dari kelompok alga coklat (Phaeophyceae) yang tersebar diperairan tropis, termasuk di Indonesia (Muslimin et al., 2017). Sampai saat ini pemanfaatan Sargassum sp. belum diketahui oleh masyarkat, bahkan beberapa kelompok masyarakat menggangap Sargassum sp. sebagai hama terhadap rumput laut utama yang dibudidaya. 
Seiring berjalannya waktu pemanfaatan Sargassum sp. berkembang cukup pesat. Pakidi et al. (2017) menyebutkan bahwa Sargassum sp. dapat dimanfaatkan sebagai antikolesterol, biofuel biofertilizer, antibakteri, antitumor, antikanker, antifouling, antivirus dan krim kosmetik. Kandungan rumput laut Sargassum sp. telah banyak diteliti sebagai bahan antioksidan alami. Sargassum sp. dapat dimanfaatkan untuk menambah nilai jual, salah satunya dengan pengeringan.

Terdapat dua macam cara pengeringan, yaitu menggunakan sinar matahari langsung dan menggunakan alat pengering. Tujuan dari proses pengeringan adalah menurunkan kadar air bahan sehingga bahan menjadi lebih awet (Risdianti et al., 2016). Pemanfaatan bahan alami Sargassum sp. dapat dilakukan dengan ekstraksi. Ekstraksi merupakan proses penarikan komponen/zat aktif suatu simplisia dengan menggunakan pelarut tertentu.

Beberapa hasil penelitian yang telah dilaporkan tentang rumput laut Sargassum sp. diantaranya dari perairan Pohuwato Kabupaten Gorontalo memiliki senyawa bioakti flavonoid, saponin, streoid, alkaloid (Manteu et al., 2018). Dengan adanya senyawa fitokimia pada Sargassum sp. dapat diasumsikan Sargassum sp. memiliki senyawa aktivitas antioksidan.

\section{METODE PENELITIAN}

\section{Bahan}

Bahan yang digunakan dalam penelitian ini terdiri dari bahan utama yaitu rumput laut (Sargassum sp.) segar yang diperoleh dari Desa Liya Bahari Indah Kabupaten Wakatobi, bahan tambahan seperti metanol teknis, Aqudes, pereaksi mayer, pereaksi wagner, pereaksi dragendrof, pereaksi liebermen, pereaksi HCL 2N, pereaksi FeCl3, serbuk magnesium, dan DPPH.

\section{Metode Pengambilan Sampel}

Pengambilan sampel rumput laut Sargassum sp. yang dilakukan pada saat air surut. Sargassum sp. yang telah diambil disimpan dalam wadah yang tertutup rapat dengan perlakuan suhu dingin untuk menjaga kesegaran rumput laut. Preparasi rumput laut
Sargassum sp. dimulai dengan proses pembersihan dan pencucian yang bertujuan untuk menghilangkan kotoran dan bakteri yang menempel. Sampel dikeringkan mengunakan suhu ruang dalam udara terbuka pada suhu $\pm 25^{\circ} \mathrm{C}$ (Luliana et al., 2016) selama 21 hari dan pengeringan oven pada suhu $40^{\circ} \mathrm{C}$ dengan lama pengeringan 30 jam, sehingga air bladder (biji) Sargassum sp. dapat mudah hancur ketika ditekan. Rumput laut Sargassum sp. yang telah kering dihaluskan dan disimpan pada plastik sampel yang nantinya akan dilakukan proses ekstraksi, modifikasi dari Indayani et al., (2019).

Ekstraksi dilakukan dengan metode maserasi (modifikasi dari Ningsih et al., 2015). Sebanyak $50 \mathrm{~g}$ bubuk Sargassum sp. direndam menggunakan pelarut metanol absolut $(200 \mathrm{ml})$ selama selama 3 hari, 5 hari, 7 hari, 9 hari, 11 hari, dan 14 hari. Selanjutnya dilakukan fitrasi menggunakan kertas saring sehingga dihasilkan filtrat dan residu (Lantah et al., 2017). Untuk memisahkan pelarut digunakan vacuum rotary evaporator pada suhu $40^{\circ} \mathrm{C}$ sampai diperoleh ekstrak kental. Pelarut yang tersisa dihilangkan dengan memanaskan ekstrak kental pada oven dengan suhu $40^{\circ} \mathrm{C}$ selama 12 jam.

\section{Analisis Fitokimia Uji Alkaloid}

Timbang sampel kemudian ekstraksi dengan kloroform amoniakal. Saring dengan kapas dan pindahkan ke tabung $A$ dan B. Pada masing-masing tabung A dan B tambahkan pereaksi Dragendorff dan pereaksi Wagner. Sampel pada tabung A positif mengandung alkaloid jika terdapat endapan berwarna kemerahan dan pada tabung $B$ terdapat endapan kecokelatan (Harborne, 1987 dalam Lantah et al., 2017).

\section{Uji Tanin}

Sampel sebanyak $2 \mathrm{gr}$ diekstraksi dengan air panas sebanyak $5 \mathrm{ml}$ selanjutnya disaring lalu dipindahkan ke tabung lain dan tambahkan $\mathrm{FeCL}_{3}$ 1\% sebanyak 2 tetes. Sampel positif mengandung tannin bila mengalami perubahan warna hijau kehitaman (Paputungan et al., 2017). 


\section{Uji Flavonoid}

Timbang sampel lalu ekstraksi dengan metanol, saring dengan kapas dan dipindahkan ke tabung lain (ekstrak metanol). Untuk pengujian digunakan pereaksi $\mathrm{H}_{2} \mathrm{SO}_{4} 2 \mathrm{~N}$, ekstrak metanol sampel ditambah 2 tetes $\mathrm{H}_{2} \mathrm{SO}_{4} 2 \mathrm{~N}$ lalu kocok kuat. Sampel positif mengandung flavonoid dengan menggunakan pereaksi $\mathrm{H}_{2} \mathrm{SO}_{4} 2 \mathrm{~N}$ bila terdapat perubahan warna kuning, merah atau cokelat yang sangat mencolok (Harborne, 1987 dalam Lantah et al., 2017).

\section{Uji Saponin}

Timbang sampel kemudian ekstraksi dengan kloroform amoniakal. Saring dengan kapas dan pindahkan ke tabung lain. Kocok kuat sampel tersebut dan diamkan selama 2 menit, kemudian tambahkan $\mathrm{HCl} 2 \mathrm{~N}$ sebanyak 2 tetes. Sampel positif mengandung saponin bila terdapat buih-buih dengan intensitas yang banyak dan konsisten selama 10 menit (Harborne, 1987 dalam Lantah et al., 2017)

\section{Uji Triterpenoid/Steroid}

Timbang sampel kemudian ekstraksi dengan etanol. Saring menggunakan kapas lalu panaskan hingga kering. Ekstraksi lagi dengan kloroform dan air (1:1). Ekstrak kloroform tersebut diteteskan pada plat tetes sebanyak 2 tetes dan biarkan sampai kering. Tambahkan asam sulfat pekat sebanyak 1 tetes dan asam asetat anhidrat sebanyak 1 tetes. Sampel positif mengandung triterpenoid apabila mengalami perubahan warna merah atau cokelat dan positif mengandung steroid apabila mengalami perubahan warna biru, ungu atau hijau (Harborne, 1987 dalam Lantah et al., 2017).

\section{Analisis Aktivitas Antioksidan}

Uji antioksidan mengacu pada metode (Sami et al., 2015). Pembuatan larutan DPPH, ditimbang sebanyak $0,01577 \mathrm{~g}$ dan dilarutkan dengan metanol absolut hingga $100 \mathrm{ml}$ dalam labu ukur. Pembuatan larutan 1000 ppm dengan cara timbang 50 mg ekstrak Sargassum sp. dan larutkan dengan metanol absolut sambil dihomogenkan, volume akhir dicukupkan metanol absolut sampai $50 \mathrm{ml}$ dalam labu ukur.

Pengukuran serapan DPPH dengan cara, larutan DPPH 0,4 mM dipipet sebanyak $1 \mathrm{ml}$ dan dicukupkan volumenya sampai $5 \mathrm{ml}$ dengan metanol absolut dalam labu terukur. Larutan ini kemudian dihomogenkan dan dibiarkan selama 30 menit, selanjutnya serapan diukur dengan spektrofotometri UV-Vis pada panjang gelombang $515 \mathrm{~nm}$

Pengujian aktivitas pengikatan radikal bebas DPPH, dilakukan dengan cara memipet masingmasing $400 \mu \mathrm{l}, 500 \mu \mathrm{l}, 600 \mu \mathrm{l}, 700 \mu \mathrm{l}$ dan $800 \mu \mathrm{l}$ dari ekstrak larutan Sargassum sp., campuran ditambah 1 $\mathrm{ml}$ DPPH 0,4 mM lalu dicukupkan volumenya sampai $5 \mathrm{ml}$ dengan methanol absolut sehingga diperoleh larutan dengan konsentrasi 100 ppm, 200 ppm, 400 ppm, 600 ppm, 800ppm, dan 1000 ppm. Selanjutnya dihomogenkan dan dibiarkan selama 30 menit, lalu diukur serapan dengan spektrofotometri UV-Vis pada panjang gelombang $515 \mathrm{~nm}$. Persen penghambat dapat dihitung dengan rumus

$$
\%=\frac{\text { Abs DPPH Blanko }- \text { Abs sisa DPPH }}{\text { Abs DPPH Blanko }}
$$

Aktivitas antioksidan dari masing-masing sampel dinyatakan dengan persen inhibisi yang mengacu pada Renhoran, (2012) dengan rumus sebagai berikut:

$$
Y=A \operatorname{Ln}(x)+B
$$

\section{Identifikasi Fitokimia}

\section{HASIL DAN PEMBAHASAN}

Hasil uji kualitatif senyawa fitokimia pada ekstrak Sargassum sp. dengan pengeringan suhu ruang dan suhu $40^{\circ} \mathrm{C}$, dapat dilihat pada Tabel 1. 
Tabel 1. Uji kualitatif senyawa fitokimia pada ekstrak Sargassum sp.

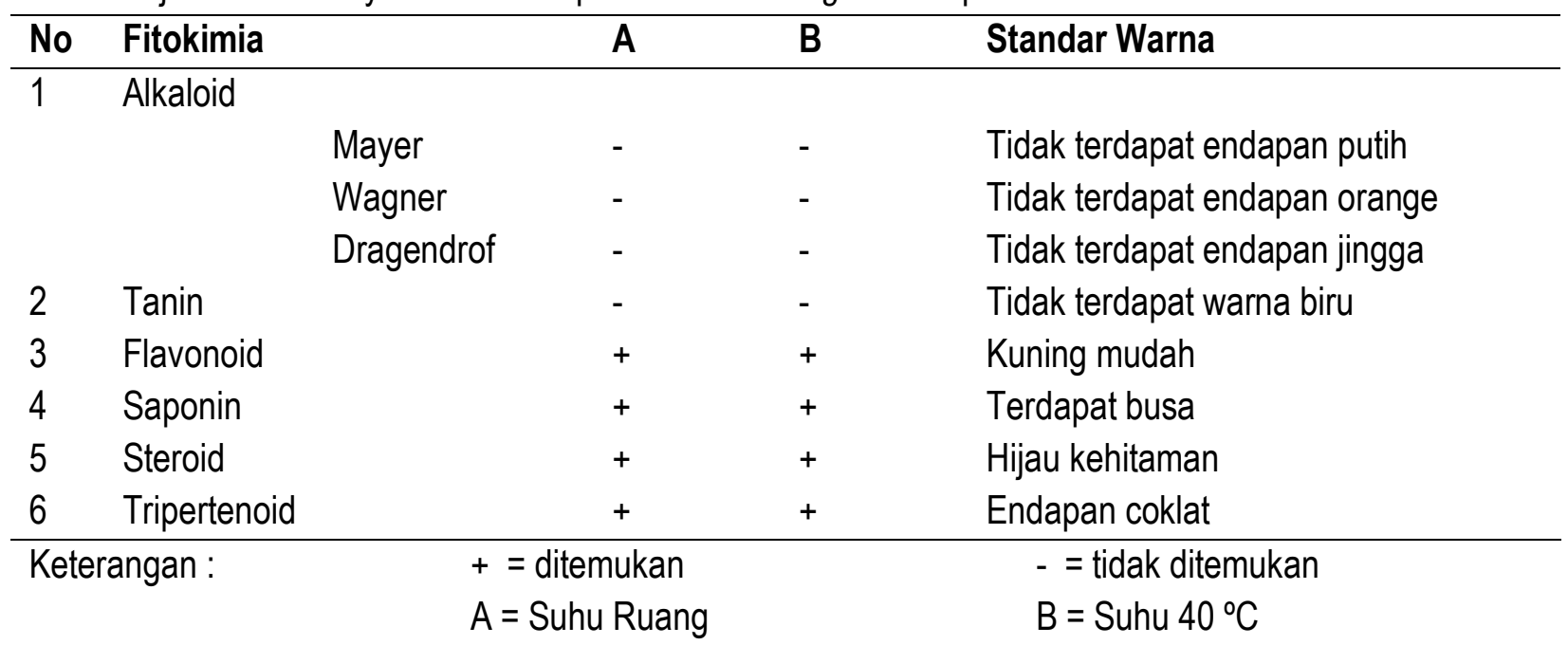

Alkaloid adalah senyawa metabolit sekunder terbanyak yang memiliki atom nitrogen (Nigrum et al., 2016). Berdasarkan hasil uji alkaloid pada ekstrak rumput laut Sargassum sp. dengan pengeringan suhu ruang dan suhu $40^{\circ} \mathrm{C}$ tidak ditemukan adanya senyawa alkaloid. Hal ini terlihat dari pereaksi Meyer yang menunjukkan tidak terdapatnya endapan putih, pereaksi wagner yang tidak terdapat endapan orange, dan dragendrof yang tidak terdapat endapan jingga. Hasil pengujian alkaloid pada penelitian ini serupa dengan penelitian Hakim et al. (2018) yang menguji kandungan alkaloid pada $S$. echinocarpum dari perairan Gunung Kidul, Yogyakarta yang diekstrak menggunakan metanol dan menunjukan $S$. echinocarpum tidak terdapat senyawa alkaloid.

Tanin merupakan suatu senyawa polifenol yang memiliki berat molekul besar yang terdiri dari gugus hidroksi dan karboksil (Sulissetiawan, 2018). Berdasarkan hasil uji tanin pada ekstrak rumput laut Sargassum sp. dengan pengeringan suhu ruang dan suhu $40^{\circ} \mathrm{C}$ tidak ditemukan adanya senyawa tanin. Hal ini terlihat dari pereaksi $\mathrm{FeCL}_{3}$ yang menunjukkan tidak terdapat perubahan warna. Hasil pengujian ini serupa dengan penelitian Diachanty et al. (2017) yang menguji tentang $S$. polycystum, P.minir, dan T.conoides dari perairan Seribu serta dikeringkan pada suhu angin selama 24 jam dan tidak tertapat senyawa tanin.

Flavonoid merupakan senyawa polifenol yang tersebar luas di alam. Berdasarkan hasil uji flavonoid pada ekstrak rumput laut Sargassum sp. dengan pengeringan suhu ruang dan suhu $40^{\circ} \mathrm{C}$ yaitu ditemukan adanya senyawa flavonoid. Hal ini terlihat terdapat perubahan warna kuning kemudahan ketika ditambahkan pereaksi $\mathrm{H}_{2} \mathrm{SO}_{4} 2 \mathrm{~N}$. Hasil pengujian flavonoid pada penelitian ini serupa dengan penelitian Mulyadi et al. (2019) yang menguji kandungan flavonoid pada Sargassum sp. dari perairan Bonerita Selatan Buton, Sulawesi Tenggara yang diekstrak menggunakan etanol dan menunjukan Sargassum sp. terdapat senyawa flavonoid.

Saponin merupakan jenis glikosida yang banyak ditemukan pada tumbuhan tingkat tinggi (Diachanty et al., 2017). Berdasarkan hasil uji saponin pada ekstrak rumput laut Sargassum sp. dengan pengeringan suhu ruang dan suhu $40^{\circ} \mathrm{C}$ yaitu ditemukan adanya senyawa saponin. Hal ini terlihat terdapat busa ketika ditambahkan pereaksi $\mathrm{HCl} 2 \mathrm{~N}$. Hasil pengujian saponin pada penelitian ini serupa dengan penelitian Mulyadi et al. (2019) yang menguji kandungan saponin pada Sargassum sp. dari perairan Bonerita Selatan Buton, Sulawesi Tenggara yang diekstrak menggunakan etanol dan menunjukan Sargassum sp. terdapat senyawa saponin.

Steroid merupakan golongan senyawa triterpenoid (Diachanty et al., 2017). Berdasarkan hasil uji steroid pada ekstrak rumput laut Sargassum sp. dengan pengeringan suhu ruang dan suhu $40^{\circ} \mathrm{C}$ yaitu ditemukan adanya senyawa steroid. Hal ini terlihat terdapatnya perubahan warna hijau kehitaman ketika 
ditambahkan pereaksi liebermen. Hasil pengujian steroid pada penelitian ini serupa dengan penelitian Siregar et al. (2012) yaitu pengujian kandungan steroid Sargassum sp. yang diperoleh dari perairan jepara serta diekstrak menggunakan metanol dan tertapat senyawa steroid.

Senyawa triterpenoid merupakan senyawa organik yang banyak ditemukan di alam. Berdasarkan hasil uji triterpenoid pada ekstrak rumput laut Sargassum sp. dengan pengeringan suhu ruang dan suhu $40^{\circ} \mathrm{C}$ yaitu ditemukan adanya senyawa triterpenoid. Hal ini terlihat terdapatnya endapan coklat ketika ditambahkan pereaksi liebermen. Hasil pengujian triterpenoid pada penelitian ini serupa dengan penelitian Hakim et al. (2018) yang menguji kandungan triterpenoid pada $S$. echinocarpum dari perairan Gunung Kidul, Yogyakarta yang diekstrak menggunakan metanol dan menunjukan $S$. echinocarpum terdapat senyawa triterpenoid.

\section{Aktivitas Antioksidan}

Hasil uji aktivitas antioksidan metode DPPH pada ekstrak Sargassum sp. dengan pengeringan suhu ruang dan suhu $40^{\circ} \mathrm{C}$, dapat dilihat pada Tabel 2.

Tabel 2. Hasil uji aktivitas antioksidan pada ekstrak Sargassum sp.

\begin{tabular}{|c|c|c|c|c|}
\hline $\begin{array}{l}\text { Metode } \\
\text { Pengeringan }\end{array}$ & Linear & Regresi & $\mathrm{IC}_{50}$ (ppm) & Nilai Rata-Rata IC 50 (ppm) \\
\hline \multirow{5}{*}{ Suhu ruang } & $R^{2}=0,9931$ & $y=0.0457 x+13.046$ & 808.56 & \multirow{5}{*}{$823,6520 \pm 24,029$} \\
\hline & $R^{2}=0,9928$ & $y=0.0459 x+13.527$ & 794.68 & \\
\hline & $R^{2}=0,9972$ & $y=0.0399 x+16.084$ & 849.90 & \\
\hline & $R^{2}=0,9815$ & $y=0.0404 x+15.795$ & 846.61 & \\
\hline & $R^{2}=0,9814$ & $y=0.0423 x+15.378$ & 818.51 & \\
\hline \multirow{5}{*}{ Suhu $40^{\circ} \mathrm{C}$} & $R^{2}=0,9884$ & $y=0.047 x+7.234$ & 909.87 & \multirow{5}{*}{$914,1920 \pm 12,228$} \\
\hline & $R^{2}=0,985$ & $y=0.046 x+8.6494$ & 899.01 & \\
\hline & $R^{2}=0,9879$ & $y=0.0452 x+8.6187$ & 915.52 & \\
\hline & $R^{2}=0,9782$ & $y=0.0452 x+7.8364$ & 932.82 & \\
\hline & $R^{2}=0,9833$ & $y=0.0462 x+7.7854$ & 913.74 & \\
\hline
\end{tabular}

Parameter untuk hasil pengujian aktivitas antioksidan adalah $\mathrm{IC}_{50}$ (inhibition concentration), semakin tinggi nilai $\mathrm{IC}_{50}$ maka semakin rendah aktivitas antiokisidan, begitupun sebaliknya semakin rendah $\mathrm{IC}_{50}$ maka semakin tinggi aktivitas antioksidan. Hasil pengujian aktivitas antioksidan metode DPPH ekstrak Sargassum sp. menunjukan pengeringan suhu ruang memiliki nilai $\mathrm{IC}_{50} 823,652$ ppm dan suhu $40^{\circ} \mathrm{C}$ memiliki nilai IC 50 914,1920 ppm. Hasil penelitian ini menunjukan bahwa perlakuan suhu ruang memiliki aktivitas antioksidan lebih tinggi dibandingkan dengan suhu $40^{\circ} \mathrm{C}$. Hasil penelitian ini serupa yang diperoleh Luliana et al. (2016) dimana aktivitas antioksidan daun senggani (Melastoma malabathricum L.) yang dikeringkan dengan udara terbuka $(54,60 \%)$ adalah lebih tinggi bila dibandingkan dengan perlakuan lain (pengeringan oven pada suhu $40^{\circ} \mathrm{C}$, pengeringan sinar matahari langsung, pengeringan sinar matahari tidak langsung dan sampel segar sebagai kontrol). Rendahnya nilai aktivitas antioksidan pada suhu $40^{\circ} \mathrm{C}$ diduga karena senyawa antioksidan memiliki sifat yang mudah rusak pada suhu yang tinggi. Pengujian aktivitas antioksidan menunjukkan proses pengeringan yang berbeda menghasilkan aktivitas antioksidan yang berbeda.

Nilai $I_{50}$ Sargassum sp. tergolong rendah yang serupa dengan beberapa peneliti. Rendahnya nilai $\mathrm{IC}_{50}$ sebanding pada penelitian Firdaus (2013) yaitu pada ekstrak menggunakan metanol $80 \%$ memiliki hasil $\mathrm{IC}_{50} 851,4833$ ppm. Pada penelitian Pahlawan (2017) pada ekstrak Sargassum sp. dari kepulauan sumbawa yaitu 376,98 ppm. Penelitian aktivitas antiosidan Edison et al. (2020) pada Sargassum plagyophyllum yang diekstrak dengan 
hexana $1105.58 \pm 16.62 \mathrm{ppm}$, etil asetat $532.42 \pm$ 7.80 ppm, dan metanol $777.79 \pm 16.82$ ppm. Penelitian aktivitas antioksidan Sunarat et al. (2019) terhadap teh rumput laut Sargassum sp. mendapatkan perlakuan terbaik pada lama perendaman 5 menit dengan $\mathrm{IC}_{50} 638 \mathrm{ppm}$ serta perlakuan terburuk pada perendaman 1 menit dengan $\mathrm{IC}_{50} 2.215 \mathrm{ppm}$.

\section{KESIMPULAN}

Berdasarkan hasil dan pembahasan, maka dapat disimpulkan sebagai berikut :

\section{DAFTAR PUSTAKA}

Aliyubi FK, Boesono H, Setiyanto. 2015. Analisis Perbedaan Hasil Tangkapan Berdasarkan Warna Lampu pada Alat Tangkap Bagan Apung dan Bagan Tancap di Perairan Muncar, Kabupaten Banyuwangi. Journal of Fisheries Resources Utilization Management and Tekhnology. 4 (2) : 93-101.

Diachanty S, Nurjanah, Abdullah A. 2017. Aktivitas Antioksidan Berbagai Jenis Rumput Laut Coklat dari Perairan Kepulaulan Seribu. JPHPI. 20 (2).

Edison, Diharmi A, Ariani NM, Ilza M. 2020 Komponen Bioaktif dan Aktivitas Antioksidan Ekstrak Kasar Sargassum plagyophyllum. JPHPI. 23 (1).

Firdaus M. 2013. Indeks Aktivitas Antioksidan Ekstrak Rumput Laut Coklat (Sargassum aquifolium). Jurnal Pengolahan Hasil Perikanan Indonesia. 16(1).

Hakim MFN, Widowati I, Sabdono A. 2018. Aktivitas Antifouling dan Karakteristik Fitokimia Ekstrak Rumput Laut Sargassum sp. dari Perairan Gunung Kidul, Yogyakarta. Journal of Marine Research. 7(3) : 201-211

Indayani MK, Asnani, Suwarjoyowirayatno. 2019. Pengaruh Metode Pengeringan yang Berbeda Terhadap Komposisi Kimia, Vitamin C dan Aktivitas Antioksidan Anggur Laut Caulerpa racemose. 2 (1).

Luliana S, Purwantu NU, Manihuruk KN. 2016. Pengaruh Cara Pengeringan Simplisia Daun Sanggani (Melastoma malabathricum L.) Terhadap Antivitas Antioksidan Menggunakan Metode DPPH (2,2-difenil-1-pikrilhadrazil). 3 (3). ISSN 2407-2354.
1. Fitokimia pada Sargassum $\mathrm{sp}$. yang dikeringkan pada suhu ruang dan suhu $40^{\circ} \mathrm{C}$ ditemukan adanya flavonoid, saponin, triterpenoid dan steroid sedangkan alkaloid dan tannin tidak ditemukan.

2. Nilai aktivitas antioksidan pada ekstrak metanol Sargassum sp. dengan pengeringan suhu ruang (IC 50 823,652 ppm) menunjukkan lebih besar dibandingkan dengan pengeringan suhu $40^{\circ} \mathrm{C}$ (IC 50 914,1920 ppm).
Lantah PL. Montolalu LADY. Reo AR. 2017. Kandungan Fitokimia dan Aktivitas Antioksidan Ekstrak Metanol Rumput Laut Kappaphycus alvarezii. Jurnal Media Teknologi Hasil Perikanan. 5 (3).

Mulyadi, Nur I, Ida W. 2019. Uji Fitokimia Ekstrak Bahan Aktif Rumput Laut Sargassum sp. Journal of Fishery Science and Innovation. 3 (1): 14-17.

Manteu SH, Nurjanah, Nurhayati T. 2018. Karakterisitik Rumput Laut Cokelat (Sargassum policystum dan Padina minor) dari Perairan Pohuwato Provinsi Gorontalo. JPHPI 21 (3).

Muslimin, Sari WKP. 2017. Budidaya Rumput Laut Sargassum sp. dengan Metode Kantong pada Beberapa Tingkat Kedalaman di Dua Wilayah Perairan Berbeda. Jurnal Riset Akuakultur, 12 (3) : 221-230

Ningrum R, Purwanti E, Sukarsono. 2016. Identifikasi Senyawa Alkaloid dari Batang Karamunting (Rhodomyrtus tomentosa) sebagai Bahan Ajar Biologi untuk SMA Kelas X. Jurnal Pendidikan Biologi Indonesia. 2 (3) : 231-236.

Ningsih G, Utami SR, Nugrahani RA, 2015, Pengaruh Lamanya Waktu Ekstraksi Remaserasi Kulit Buah Durian Terhadap Rendemen Saponin dan Aplikasinya Sebagai Zat Aktif Anti Jamur. 4 (1).

Pakidi CS, Suwoyo H S. 2017. Potensi dan Pemanfaatan Bahan Aktif Alga Coklat Sargassum sp. Jurnal IImu Perikanan. 6 (1).

Paputungan Z, Wonggo D, Kaseger BE. 2017. Uji Fitokimia dan Aktivitas Antioksidan Buah Mangrove sonneratia alba di Desa Nunuk 
Kecamatan Pinolosian Kabupaten Bolaang

Research. 1 (2). 152-160

Mongondow Selatan.

Podungge A, Damongilala LJ, Mewengkang HW.

2018. Kandungan Antioksidan pada Rumput

Laut Eucheuma spinosum yang Diekstrak dengan Metanol dan Etanol. Jurnal Media Teknologi Hasil Perikanan. 6 (1).

Pahlawan $\mathrm{CH}$. Potensi Fraksi Aktif Fukosantin dan Ekstrak Rumput Laut Coklat (Sargassum sp. dan Turbinaria sp.) Menggunakan Berbagai Pelarut Organik sebagai Antibakteri dan Antioksidan. Program Studi Teknobiologi Fakultas Teknobiologi. Universitas Teknologi Sumbawa. 2017

Risdianti D, Murad, Putra GMD. 2016. Kajian Pengeringan Jahe (Zingiber Officinale Rosc) Berdasarkan Perubahan Geometrik dan Warna Menggunakan Metode Image Analysis.Jurnal IImiah Rekayasa Pertanian dan Biosistem. 4 (2).

Renhoran M. Aktivitas Antioksidan dan Antibakteri Ekstrak Sargassum polycystum. Departemen Teknologi Hasil Perairan. Fakultas Perikana dan IImu Kelautan. Institut Pertanian Bogor. 2012

Sinurat E, Suryaningrum TD. 2019. Aktivitas Antiosidan dan Sifat Sensori Teh Rumput Laut Sargassum sp. Berdasarkan Variasi Lama Perendaman. JPHPI. 22 (3).

Sami FJ, Rahimah S. 2015. Uji Aktivitas Antioksidan Ekstrak Metanol Bunga Brokoli (Brassica oleracea L. var. Italica) dengan Metode DPPH (2,2 diphenyl-1-picrylhydrazyl) dan Metode ABTS (2,2 azinobis (3-etilbenzotiazolin)-6asam sulfonat). Jurnal Fitofarmaka Indonesia. $2(2)$.

Sulissetiawan A. Optimasi Formula Rumput Laut Coklat Sargassum sp., Kayu Manis (Cinnamomum burmani), dan Daun Sirsak (Annona muricata L), sebagai Minuman Fungsional Penghambat a-Glukosidase. Skripsi. Program Studi Teknologi Hasil Perikanan. Jurusan Manajemen Sumberdaya Perairan. Fakultas Perikanan dan IImu Kelautan. Universitas Brawijaya. 2018.

Siregar AF, Sabdono A, Pringgenies D. 2012. Potensi Antibakteri Ekstrak Rumput Laut Terhadap Bakteri Penyakit Kulit Pseudomonas aeruginosa, Staphylococcus epidermidis, dan Micrococcus luteus. Journal Of Marine 